Acreditamos que a forma da espermateca não seja adequada para uma identificação segura para estas subespécies, considerando-se que a mesma pode variar dentro de uma mesma população (fig. 2 e 3). Também há a considerar que a espermateca pode posicionar-se diferentemente por ocasião da montagem na lâmina, tomando formas variáveis, o que pode conduzir a erros de diagnóstico, se o pesquisador não estiver atento.

Quanto a um status definitivo de populações desta espécie, este só será possível quando forem estudados, conjuntamente, exemplares de toda área de dispersão de P. klagesi, que presentemente se encontram distribuídos pelo Brasil, Equador, Colômbia, Venezuela, Trinidade, Costa Rica (Mendez, 1977) e Guiana Francesa (Beaucournu, 1969).

\section{SUMMARY}

The present note is the first record of the flea, Polygenis klagesi samuelis (J. \& R., 1923), for Brazil. The fleas were collected at Manaus, Amazonas.

\section{Agradecimento}

$\mathrm{O}$ autor agradece ao Dr. Pedro Marcos Linardi da UFMG, pela crítica do manuscrito.

\section{REFERENCIAS BIBLIOGRÁFICAS}

BEAUCOURNU, J.C.

1969 - Sur quelques siphonaptères (Insecta) de Guyane Française. Arch. Inst. Pasteur Guiane Française, 21 (526): 363-366.

GUIMARÃES, L.R.

1972 - Contribuição à epidemiologia da peste endêmica no nordeste do Brasil e Estado da Bahia. Estudo das pulgas encontradas nessa região. Rev. Bras. Malariol. D. Trop., 24 (1-4): 95-164.

JORDAN, K. \& ROTHSCHILD, N.C.

1923 - On the genera Rhopalopsyllus and Parapsyllus. Ectop., 1: 320-370.

MACHADO-ALLISON, C.E.

1967 - Sobre alguns ectoparasitas de mamiferos de la biota amazonica. Atas do Simpósio sobre a Biota Amazônica, 5 (zoologia): 365372 .

MACHADO-ALLISON, C.E. \& MCLURE, M.T.

1963 - Notas scbre Rhopalopsyllidae. III. Consideraciones sobre las subespécies de Tiamastus (Gephyropsylla) klagesi (Rhopalopsylloidea). Acta Biol. Venez., 3 (27): 421-436.

MENDEZ, E.

1977 - Mammalian-siphonapteran associations, the environment, and biogeography of mammals of southwestern Colombia. Quaest. Ent., 13: 91-182.

TIPTON, V.J. \& MACHADO-ALLISON, C.E.

1972 - Fleas of Venezuela. Brigham Young Univ. Sci. Bull., Biol. series, 17: (6): 1-115.

(Aceito para publicação em 29/09/81)

\title{
Tabanidae (Diptera) da Amazônia, I - Uma nova armadilha suspensa e primeiros registros de mutucas de copas de árvores
}

\author{
José Albertino Rafael \\ Instituto Nacional de Pesquisos \\ da Amaxônio, Manaus \\ Inocêncio de Sousa Gorayeb \\ Museu Paraense Emilio \\ Goeldi, Belém
}

\section{INTRODUÇÃo}

Um grande passo foi dado nas pesquisas que estão sendo executadas sobre tabanídeos na Amazônia, com a vinda do Dr. G.B. Fairchild nos meses de junho a agosto de 1981, pe. lo projeto "Manejo Ecológico e Exploração da Floresta Tropical Úmida". Na oportunidade, as necessidades mais prementes de pesquisas para ampliação do conhecimento sobre esses dipteros na região neotropical foram discutidas e delineadas. Alguns métodos de coletas de tabanídeos foram experimentados, discutidos e aperfeiçoados, e algumas coletas foram executadas em pequenas excursões nas proximidades de Belém e Manaus. Os resultados des- 
sas pesquisas serão publicados iniciando uma série de trabalho sob o título "Tabanidae (Diptera) da Amazônia", sendo esse o primeiro deles.

Os métodos conhecidos de coleta de insetos, principalmente tabanídeos, nas copas das árvores são poucos e podem ser encontrados nos trabalhos de Fairchild (1953), Roberts (1976), Montgomery et al., s/d e Penny \& Arias (1982).

Os autores alertam para o fato de algumas espécies de tabanídeos serem representadas somente por um, dois ou poucos exemplares nas coleções e de as mesmas ocorrerem nas copas das árvores, habitat pouco explorado pelos coletores. Tendo-se como base essa observação e a necessidade de capturas nesses ambientes, construiu-se uma armadiIha, a "Armadilha Suspensa", descrita neste trabalho. Nos estratos superiores da floresta, registraram-se os representantes de tabanídeos e constatou-se a eficiência da armadilha.

\section{DESCRIÇÃo DA ARMAdILHA SUSPENSA}

Consiste de três peças: septo inferior, cobertura e frasco coletor (Fig. 1 e 2). A cobertura é uma pirâmide com quatro peças triangulares de tecido fino (filó), costuradas entre si. Cada peça tem $1,5 \mathrm{~m}$ de base por $1,5 \mathrm{~m}$ de altura. A $10 \mathrm{~cm}$ da base de cada peça é costurada, internamente, uma faixa de pano que possibilita a passagem de canos PVC de $1 / 2$ polegada com $1,35 \mathrm{~m}$ de comprimento. Estes são encaixados através de cantos PVC- $90^{\circ}$ (cotovelos), formando um quadrado. No ápice das qua-, tro peças de filó fica uma abertura que permite o encaixe do frasco coletor, preso à armadilha por uma braçadeira graduável de metal (para mangueiras de borracha). O frasco coletor pode ser adaptado de acordo com as conveniências de cada construtor. Utilizamos um frasco de plástico transparente, de $10 \times 10 \times$ $15 \mathrm{~cm}$, com um tubo PVC de $5 \mathrm{~cm}$ de comprimento por 3 polegadas de diâmetro, fazendo conecção entre as peças de pano e o frasco (a braçadeira prende o pano em volta deste anel de PVC). Um funil piramidal ou redondo, de acrílico, plástico ou vidro, com dois centí-

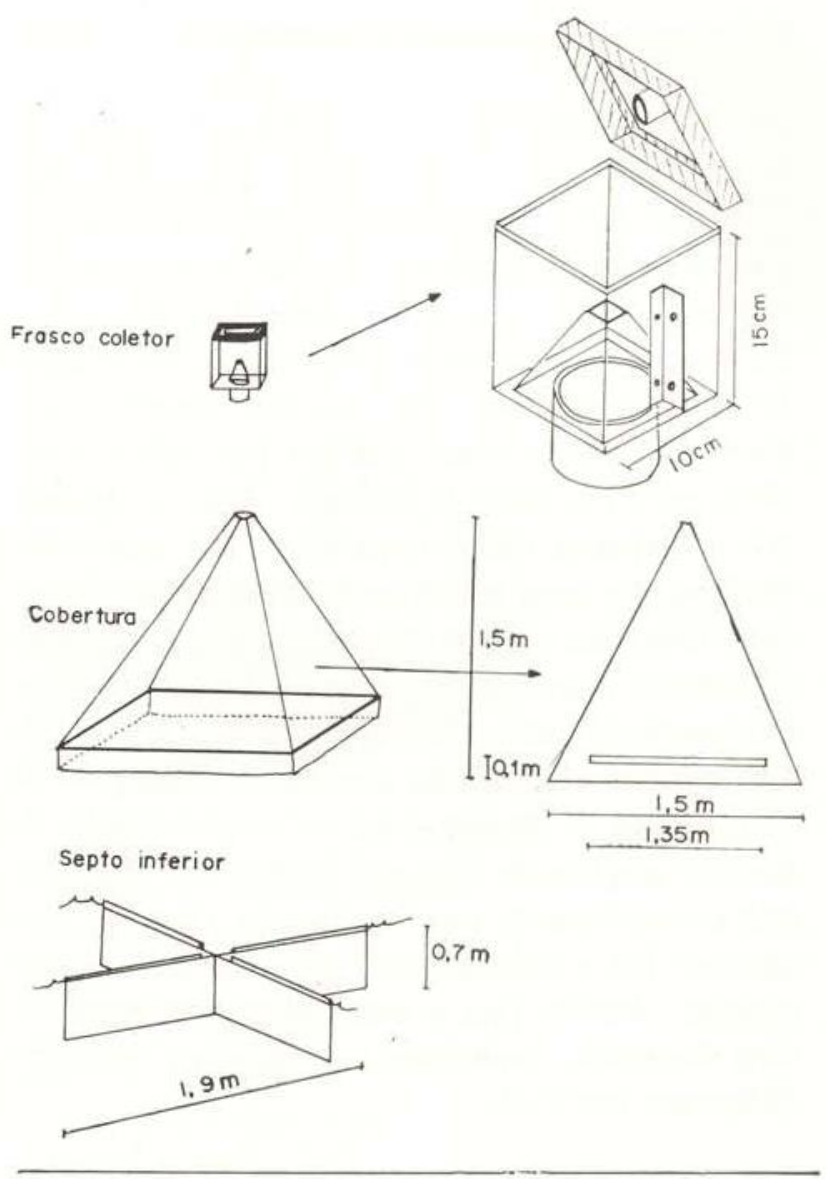

Fig. 1 - Esquema fara montagem e dimensões do frasco coletor, cobertura e septo inferior da Armadilha Suspensa.

metros de abertura superior, é colocado no interior do frasco para impedir a saída dos insetos e limitar o tamanho dos que entram. O tubo mortífero com cianeto de potássio ( $\mathrm{KCN}$ ) é adaptado de uma caixinha plástica de filme fotográfico presa na tampa transparente do frasco coletor com cola ou parafuso. Lateralmente ao frasco coletor, é presa uma peça de alumínio ou acrílico de $10 \mathrm{~cm}$ com dois orifícios, por onde passa a corda que sustentará a armadilha. O septo inferior pode ser feito de diferentes materiais e cores. Utilizou-se pano e plástico pretos. O septo constitui-se de duas peças de $1,9 \mathrm{~m}$ de comprimento por $0,70 \mathrm{~m}$ de altura, costurados no meio, de modo a fazer uma peça única em forma de $\mathrm{X}$. Na parte superior do septo, costura-se uma bainha para a passagem de um barbante resistente que será amarrado nos cantos do quadrado de PVC, unindo, dessa maneira, o septo à cobertura. 
COLOCAÇÃo DA ARMADILHA SUSPENJA

Para colocação da armadilha na copa das árvores, escolhe-se um galho qualquer, amarra-se um peso num barbante fino e resistente e atira-se sobre o galho. $\mathrm{O}$ arremesso pode ser realizado com uma arma especial de calibre 22, com uma baladeira (estilingue), ou mesmo arremesso manual sem auxílio desses materiais. No último caso, a altura em que a armadilha será montada é limitada. Depois de passar o barbante sobre o galho, faz-se sua substituição por uma corda mais resistente. Amar. ra-se uma das pontas da corda na base do frasco coletor e a outra na própria corda (próximo do frasco coletor), de modo a fazer um círculo que envolve o galho da árvore. A vantagem da corda fazer o círculo está na possibilidade de ocorrer engate de nós nos galhos ou seu peso não ser suficiente para a descida. Quando isso ocorrer, há a possibilidade da armadilha ser puxada. Assim que a armadilha estiver na altura desejada, prende-se a corda em qualquer substrato próximo.

\section{VANTAGENS DA ARMADILHA SUSPENSA}

A armadilha em questão apresenta as seguintes vantagens sobre outras com a mesma linha de captura de insetos:

a - é leve e de fácil transporte, cabendo dentro de um saco plástico de 20 litros, sem considerar os canos PVC. Seu processo de montagem é prático e fácil.

Peças da Armadilha Suspensa e seus respectivos pesos $(g)$

Canos e cantos PVC .......... 750

Frasco coletor ................ 310

Cobertura .................. 330

Septo inferior (plástico) ......... 670

Pequeno frasco com KCN ....... 10

Corda de nylon de $5 \mathrm{~mm}$ de diâme-

tro com $50 \mathrm{~m}$............. 1000

$$
\text { Peso Total } 3070
$$

b - pode ser montada em diferentes alturas, explorando diferentes estratos no mesmo local da floresta (fig. 3).

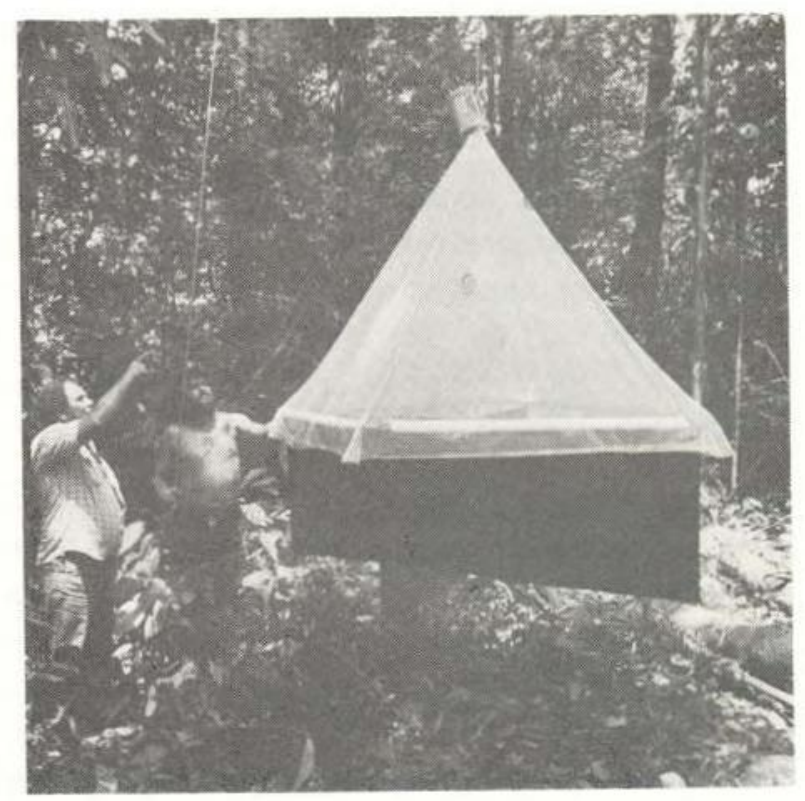

Fig. 2 - Armadilha Suspensa pronta para funcionamento.

c - é de fácil construção e pouco onerosa.

$\mathrm{d}$ - os septos inferiores podem ser de várias cores, possibilitando o estudo da atração de insetos por diferentes espectros (Bracken et al., 1962; Roberts, 1970).

e - quando suspensa, fica movimentando-se com ação dos ventos, tanto no sentido horizontal quanto no seu eixo próprio, sensibilizando visualmente os tabanídeos e alguns outros insetos.

$f$ - forma um contraste bem visível entre a cobertura e o septo inferior e destes com o fundo do ambiente, o que também sensibiliza visualmente muitos insetos (Roberts, 1970).

$\mathrm{g}$ - pode ser montada em pastagens ou áreas abertas, sem a necessidade de protegêla, pois pode ficar a uma altura que os animais (gados) não alcançam.

$\mathrm{h}$ - funciona ininterruptamente e os insetos podem ser retirados cada 3 ou 4 dias, sem a necessidade de visitas diárias.

i - pode ser adaptada com $\mathrm{CO}_{2}$ (gelo seco) para maior eficiência na captura de insetos hematófagos, sendo desnecessário deslocar uma pessoa até a copa das árvores para captura dos mesmos 


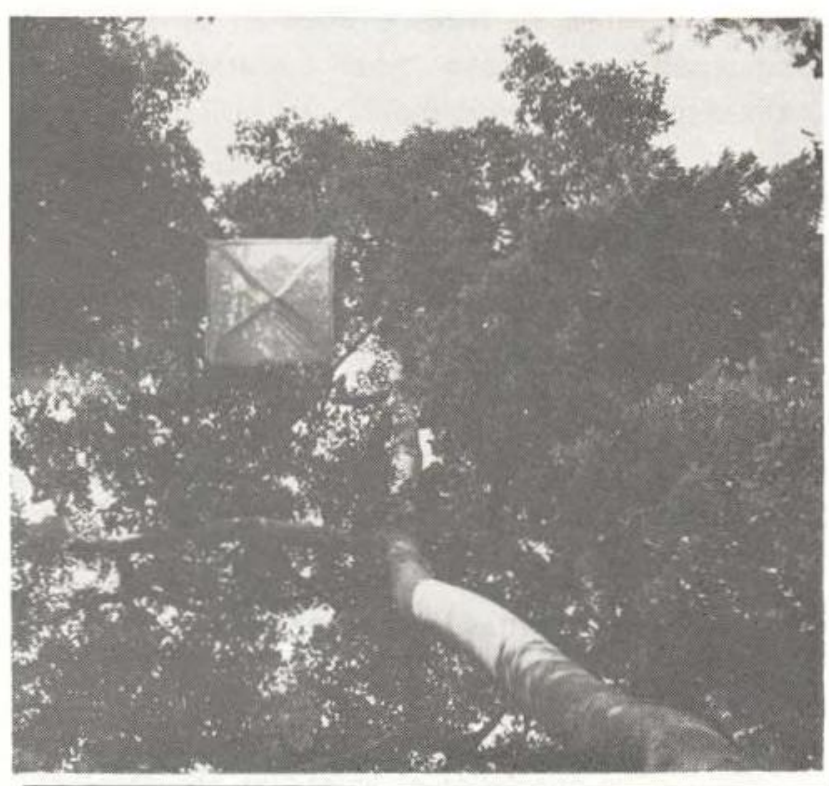

Fig. 3 - Armadilha Suspensa na copa das ârvores.

j - iscas que atraem outros insetos podem ser utilizadas na armadilha possibilitando a coleta de grupos de interesse de diferentes estudos.

I - com pequenas adaptações pode funcionar como armadilha de eclosão.

A armadilha foi montada em florestas nas proximidades de Belém e Manaus, entre 15 e $25 \mathrm{~m}$ de altura, tendo capturado as espécies de tabanídeos listadas na tabela 1. No estrato inferior, funciona bem, substituindo eficientemente a armadilha de Malaise e capturando a grande maioria das espécies que aí voam.

\section{DISCUSSÃo}

Os insetos que habitam os estratos superiores das florestas na Amazônia são pouco representados em coleções e certamente várias espécies desconhecidas existem nesses habitats, isso sem se falar da falta de informações sobre biologia, ecologia e comportamento das mesmas. Os métodos de coleta de insetos nesses estratos são poucos, onerosos e até certo ponto pouco práticos. Fairchild (1953) estudou os tabanídeos atraídos com isca humana em plataformas de 6 a $25 \mathrm{~m}$ de altura no Panamá. Roberts (1976) utilizou armadilhas de Malaise em plataformas e suspendeu-as
TABELA 1 - Tabanídeos capturados em copa de árvores, entre 15 e $25 \mathrm{~m}$ de altura, nos meses de agosto a dezembro de 1981, nos arredores de Belém e Manaus

\begin{tabular}{|c|c|c|c|c|}
\hline \multirow[t]{2}{*}{. } & \multicolumn{2}{|c|}{ Belém } & \multicolumn{2}{|c|}{ Manaus } \\
\hline & $\widehat{\delta}$ & ? & o & q \\
\hline *Acanthocera marginalis Walk. & & $x$ & & $x$ \\
\hline Chrysops equadorensis Lutz & & $x$ & & \\
\hline - Diachlorus aitkeni Fchld. \& Ortiz & & $x$ & & $\mathrm{x}$ \\
\hline Diachlorus curvipes (Fab.) & & $x$ & & \\
\hline - Diachlorus fuscistigma Lutz & & $x$ & & \\
\hline - Diachlorus podagricus (Fab.) & & $\mathrm{x}$ & & $x$ \\
\hline Diachlorus scutellatus (Macq.) & & $x$ & & $\mathrm{x}$ \\
\hline Dichelacera cervicornis (Fab.) & & $x$ & & \\
\hline - Dichelacera damicornis (Fab.) & & $x$ & & $\mathrm{x}$ \\
\hline Fidena freemani Barr. & & & & $\mathrm{x}$ \\
\hline Fidena pseudoaurimaculata (Lutz) & & & & $\mathrm{x}$ \\
\hline - Philipotabanus stigmaticalis (Kröb) & & & & $\mathrm{x}$ \\
\hline Poeciloderas quadripunctatus (Fab.) & & & $\mathrm{x}$ & \\
\hline Stibasoma currani (Phil.) & & & & $x$ \\
\hline - Stibasoma fulvohirtum (Wied.) & & & & $x$ \\
\hline Stypommisa captiroptera (Kröb) & & & $x$ & \\
\hline Stypommisa (?) glendicolor (Lutz) & & & $\mathrm{x}$ & $x$ \\
\hline - Stypommisa modica (Hine) & & $x$ & & $\mathrm{X}$ \\
\hline Tabanus albopruinosus Kröb. & & $\mathrm{x}$ & & $\mathrm{x}$ \\
\hline Tabanus dorsiger Wied. & $\mathrm{x}$ & $x$ & & \\
\hline - Tabanus sannio Fchld. & & & $x$ & $x$ \\
\hline Tabanus trivittatus Fab. & & $\mathrm{x}$ & & $x$ \\
\hline
\end{tabular}

(*) - Espécies que ocorrem preferencialmente na copa dos árvores.

até $4,2 \mathrm{~m}$ em diferentes alturas para estudar a distribuição por estratificação. Montgomery et al. (s.d.) utilizou um sistema de borrifação de inseticidas na copa das árvores e coletaram os insetos mortos que caíam sobre lençóis abertos sob as árvores. Estes métodos apresentam esforços e gastos desnecessários, sendo, por isso, não práticos ou pouco recomendáveis. O deslocamento de uma pessoa até plataformas construídas nas árvores envolve um grande esforço diário. O sistema de plataformas e cabos para suspender, na floresta, armadilhas de Malaise convencionais é dispendioso, difícil e exige grande esforço, ou a borrifação de inseticidas na copa de árvores que exige a derrubada da sub-mata para armação de lençóis não se recomenda, tanto pela alteração química ambiental, como pela agressão física à sub-mata. 
A Armadilha Suspensa descrita neste trabalho é apresentada como um método alternativo que pode substituir, a contento, os acima citados, sem envolver grande esforço nem modificar ou agredir o ambiente natural, pois é leve, de fácil montagem, pouco onerosa, prática e com as demais vantagens já citadas neste trabalho.

Os primeiros resultados com esta armadiIha mostraram uma fauna distinta que está ameaçada com o rápido desmatamento da floresta amazônica para a agricultura, pecuária e demais fins. Outras áreas devem ser exploradas e provavelmente mostrarão fauna diversificada, como já foi observado para a fauna dos estratos inferiores.

Nas áreas em que se realizaram is cole. tas, certas espécies foram restritas à copa das árvores, enquanto outras ocorreram raramente nesse estrato, sendo mais abundantes próximo do solo (tabela 1).

Os trabalhos preliminares indicam que existem várias espécies desconhecidas. Assim as pesquisas sobre tabanídeos devem ser levadas à frente com o emprego dos diferentes métodos de coleta para ampliar o conhecimento da fauna amazônica. Os tabanídeos são insetos hematófagos, que, pela sua potencialidade de transmitir agentes patogênicos, merecem ser melhor estudados na região.

\section{Agradecimentos}

Aos pesquisadores Eduardo Lleras, Paulo F. Buhrnhein e Adelmar G. Bandeira, pela leitura do manuscrito; aos técnicos Francisco F.
Ramos, Ramiro B. Neto e José E. Bindá, pela dedicação e interesse nos experimentos no campo e no laboratório.

\section{SUMMARY}

A new method for capturing tabanids and other insects in the canopy and other tree strata, the "Suspended Trap", is described here. Its advantages and some comparative aspects with other methods are discussed, and a list is preseñted of horse-flies captured using the new method in treetops near Manaus and Belém, Brazil.

\section{REFERENCIAS BIBLIOGRAFICAS}

ERACKEN, G.K.; HANEC, W. \& THORSTEINSON, A.J.

1962 - The orientation of horse-flies and deer-flies (Diptera: Tabanidae) II. The role of some visual factors in attractiveness of decoy siIhouettes. Can. J. Zool., 40: 685-695.

FAIRCHILD, G.B.

1953 - Arboreal Tabanidae in Panama. Proc. ent. Soc. Wash., 55 (5): 239-243.

MONTGOMERY, G.G.; LUBIN, Y. \& ADIS, J.

$\mathrm{s} / \mathrm{d}$ - Diversity and biomass of arthropods in the canopy of inundated and terra-firme forests near Manaus, Brasil: a preliminary report. (Em preparação).

PENNY, N.D. \& ARIAS, J.R.

1982 - Insects of an Amazon forest. New York, Columbia University Press. 269pp.

ROBERTS, R.H.

1970 - Color of Malaise trap and the collection of Tabanidae. Mosquito News, 30 (4): 567-571.

1976 - Altitude distribution of Tabanidae as determined by Malaise trap collections. Mosquito News, 36 (4): $518-520$.

(Aceito para publicação em 29/03/82 Prioridade autorizada) 